\title{
Interaction Between Lead Iron Niobate/Tungstate Ceramics and Silver/Palladium Metals
}

\author{
Chung-Hsin Lu* \& Jiun-Yee Lin \\ Department of Chemical Engineering, National Taiwan University, Taipei, Taiwan
}

(Received 26 November 1995; accepted 8 March 1996)

\begin{abstract}
The interactions between ferroelectric $\mathrm{Pb}\left(\mathrm{Fe}_{1 / 2} \mathrm{Nb}_{1 / 2}\right) \mathrm{O}_{3}$ (PFN)/ $\mathrm{Pb}\left(\mathrm{Fe}_{2 / 3} \mathrm{~W}_{1 / 3}\right) \mathrm{O}_{3}$ (PFW) perovskite ceramics and silver/palladium metals were systematically investigated through the phase formation and microstructural variation. Silver did not react with PFN/PFW ceramics after heating to $900^{\circ} \mathrm{C}$, and perovskite grains were only distributed among the matrix of silver. After being heated with $70 \mathrm{Ag} / 30 \mathrm{Pd}$ at $900^{\circ} \mathrm{C}$, no perovskite phases were significantly altered; however, in the PFN-rich ceramics, the palladium content in the alloy decreased along with the formation of PdO. Pure palladium was found to have the highest reactivity with PFN/PFW ceramics. The reactions between palladium and ceramics occurred vigorously from $850^{\circ} \mathrm{C}$ and resulted in markedly different microstructures. Palladium caused PFW to decompose into $\mathrm{PbWO}_{4}$ and $\mathrm{Pb}_{2} \mathrm{WO}_{5}$, and also led to the dissociation of PFN/PFW ceramics to produce pyrochlore phases and $\mathrm{Fe}_{2} \mathrm{O}_{3}$. The reactivity of palladium with perovskite phases was positively correlated with the PFN content in specimens. In addition, increasing the PFN content also tended to postpone the reduction process of PdO to palladium. (C) 1997 Elsevier Science Limited and Techna S.r.l. All rights reserved
\end{abstract}

\section{INTRODUCTION}

The multilayer ceramic capacitor (MLC) industry has been growing rapidly in the past few decades as a result of the requirement for miniaturization of electronic circuits. During the fabrication of MLCs, the dielectric ceramic layers are co-fired with the metal electrode layers at elevated temperatures. After co-firing, satisfactory physical integrity between the two kinds of layers is required. The incompatibility between ceramics and electrodes, shown by effects such as delamination or separation, will cause the formation of cracks when the parts are subjected to thermal stress during soldering for surface mount applications. ${ }^{1,2}$ Furthermore, the chemical interactions of ceramics with electrode metals have adverse effects on the electric performance of MLCs with regard to the insulation resistivity and dielectric char-

*To whom correspondence should be addressed. acteristics of dielectric ceramics. ${ }^{3}$ Therefore, research into the potential interactions between ceramics and electrode metals becomes a crucial issue for MLCs.

Relaxor ferroelectric lead iron niobate $\left[\mathrm{Pb}\left(\mathrm{Fe}_{1 / 2} \mathrm{Nb}_{1 / 2}\right) \mathrm{O}_{3}\right.$, abbreviated to PFN] and lead iron tungstate $\left[\mathrm{Pb}\left(\mathrm{Fe}_{2 / 3} \mathrm{~W}_{1 / 3}\right) \mathrm{O}_{3}\right.$, abbreviated to $\mathrm{PFW}$ ] are two well-known, important dielectric materials for MLC applications. ${ }^{4-11}$ These two materials react at elevated temperatures to form complete solid solutions which exhibit the perovskite structure. When the content of PFN in the solid solution is increased, the dielectric constant maximum becomes sharper, and the Curie temperature is raised, associated with an increase in sintering temperature. ${ }^{12}$ Adjusting the composition to be 0.7PFN-0.3PFW can shift the Curie temperature to be near room temperature, and this material can be sintered at temperatures as low as $900^{\circ} \mathrm{C}^{12}$ In light of the advantages of low-temperature sintering characteristics and high 
permittivity, the PFN/PFW-based system has been applied in MLCs where the inexpensive silver/ palladium alloy is used as inner electrodes for cost saving. In spite of the application of PFN/PFW ceramics to MLCs, the interaction between the ceramics and electrodes with regard to the reactivity and stability of ceramics with electrode metals has not yet been thoroughly investigated.

The primary purpose of this study is to elucidate the interaction between the PFN/PFW ceramics and silver/palladium metals. The phase formation and the microstructural variation during the reaction were investigated. The PFN/PFW ratio in the perovskite compounds was varied in order to examine the influence of composition on the stability of perovskite compounds with metals. Moreover, the effects of the composition of ceramics on the oxidization and reduction reactions of metals were also studied.

\section{EXPERIMENTAL}

Proportionate amounts of reagent-grade starting materials $\left(\mathrm{PbO}, \mathrm{Fe}_{2} \mathrm{O}_{3}, \mathrm{Nb}_{2} \mathrm{O}_{5}\right.$ and $\mathrm{WO}_{3}$ ) were mixed according to the composition of $(1-x)$ PFW $-x$ PFN at $x=0,0.3,0.7$ and 1 . The specimens with a composition of $x=0,0.3,0.7$ and 1 are designated as PFW, PF3, PF7 and PFN, respectively. These raw materials were ball-milled for $48 \mathrm{~h}$ with ethyl alcohol, using zirconia balls. After being dried in a rotary evaporator, the mixed powders were uniaxially pressed into disks of $8 \mathrm{~mm}$ in diameter under $196 \mathrm{MPa}$. For synthesizing $\mathrm{PFW}$, the precursors were calcined at $870^{\circ} \mathrm{C}$ for $2 \mathrm{~h}$. For the other three specimens, the mixed powders were heated at $900^{\circ} \mathrm{C}$ for $2-4 \mathrm{~h}$. After the complete perovskite phases were formed in the specimens, the obtained ceramic powders were mixed, respectively, with an equal weight of metal powders. Pure silver, pure palladium, and a mixture of silver and palladium (with $70 \mathrm{~mol} \%$ of silver) were used. The mixtures of ceramic and metal powders were heated for $2 \mathrm{~h}$ at temperatures ranging from $800^{\circ} \mathrm{C}$ to $900^{\circ} \mathrm{C}$. The compounds present in the specimens were identified via $\mathrm{X}$-ray powder diffraction (XRD) analysis using $\mathrm{CuK} \alpha$ radiation. Microstructural evolution of the specimens was studied via a scanning electron microscopc (SEM) coupled with energy dispersive $\mathrm{X}$-ray spectroscopy (EDS). Differential thermal analysis (DTA) and thermogravimetry analysis (TGA) were performed to examine the oxidation/ reduction reactions of metals and the weight change of specimens during heating in air.

\section{RESULTS AND DISCUSSION}

\subsection{Interaction between PFN/PFW ceramics and silver}

Four kinds of perovskite powders (PFW, PF3, PF7 and PFN) were heated with silver up to $900^{\circ} \mathrm{C}$. The XRD analysis performed on the heated specimens revealed that all of the perovskite patterns remained unchanged after heating. Figure 1 illustrates the XRD patterns of the $900^{\circ} \mathrm{C}$-heated mixtures of perovskite phases and silver. As shown in this figure, the diffraction patterns of the perovskite phase and silver can be clearly distinguished, and no other compound was formed. From the results of SEM, the grains of perovskite phase were found to distribute among the matrix of silver; moreover, the original morphology of perovskite grains was maintained. The micrographs of the specimens of PFW and PF3 mixed with silver after heating to $900^{\circ} \mathrm{C}$ are shown in Fig. 2. These XRD and SEM results indicate that silver can stably coexist with PFN/PFW perovskite phases up to $900^{\circ} \mathrm{C}$ without the occurrence of chemical reactions.

\subsection{Interaction between PFN/PFW ceramics and silver/palladium}

When the mixtures of perovskite compounds and silver/palladium were heated from $800^{\circ} \mathrm{C}$ to $900^{\circ} \mathrm{C}$, no significant changes in the diffraction patterns of perovskite phases were observed. The XRD results of the $900^{\circ} \mathrm{C}$-heated specimens are shown in Fig. 3. In pure PFW, the $70 \mathrm{Ag} / 30 \mathrm{Pd}$ alloy was formed and exhibited a distinct diffraction pattern. As the PFN content in ceramics was increased, the diffraction peaks of silver/palladium became broadened and smeared into those of perovskite phases. In addition, a small amount of PdO was found in PF7 and PFN. Due to the formation of $\mathrm{PdO}$, the palladium content in the alloy was lowered, resulting in an increase of the lattice constant with the diffraction peaks shifting to the low angle side. ${ }^{13}$ The broadening of the diffraction peaks of silver/palladium and the formation of PdO imply that a partial interaction occurred between PFN-rich ceramics and silver/palladium. In contrast, PFW was chemically stable with silver/ palladium. The microstructural observation supported this inference. As seen in Fig. 4(a), the PFW grains were distributed in the metal matrix without changing their morphology. On the other hand, in the PFN specimen [see Fig. 4(b)], although the PFN grains can be still recognized, the matrix of metal became discontinuous with the formation 


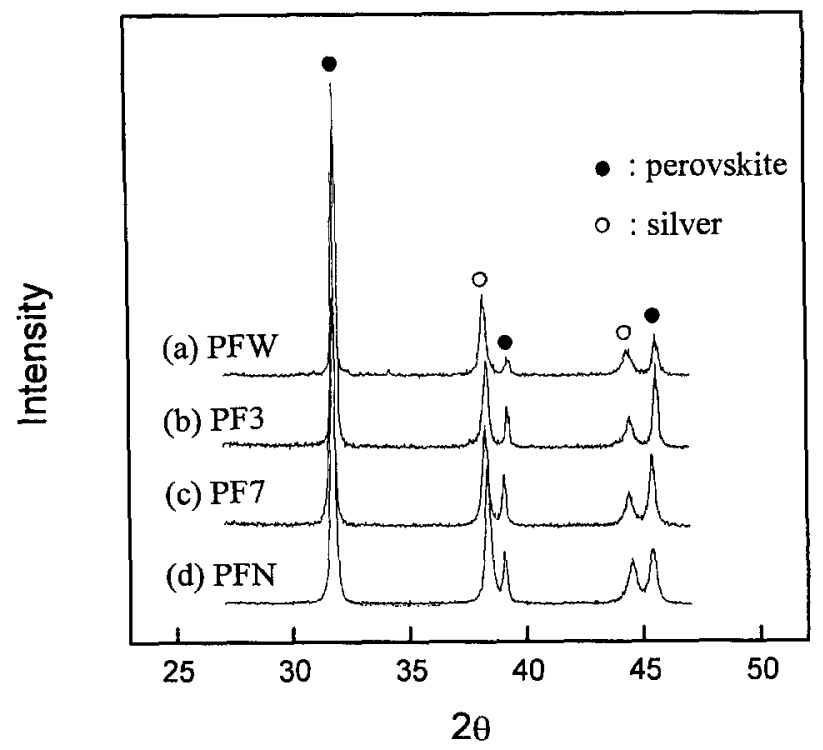

Fig. 1. X-ray diffraction patterns for the specimens of silver mixed with (a) PFW, (b) PF3, (c) PF7 and (d) PFN ceramics after heating at $900^{\circ} \mathrm{C}$ for $2 \mathrm{~h}$.

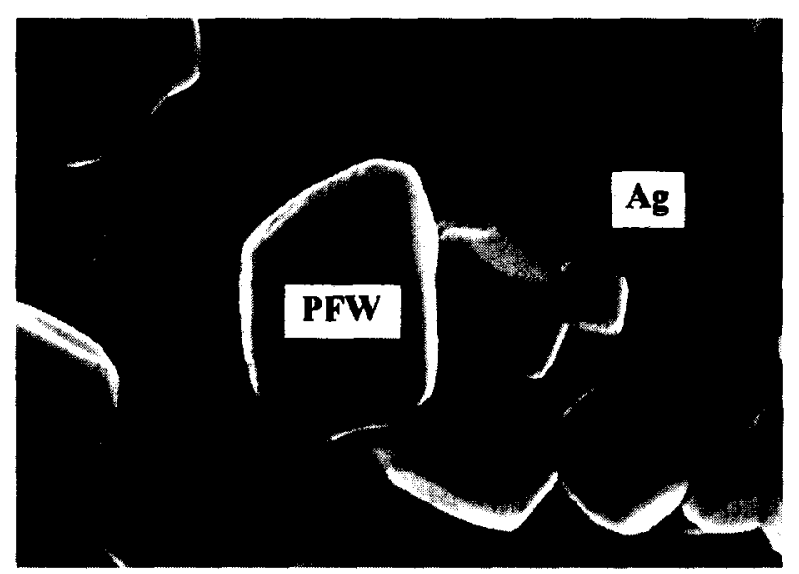

(a)

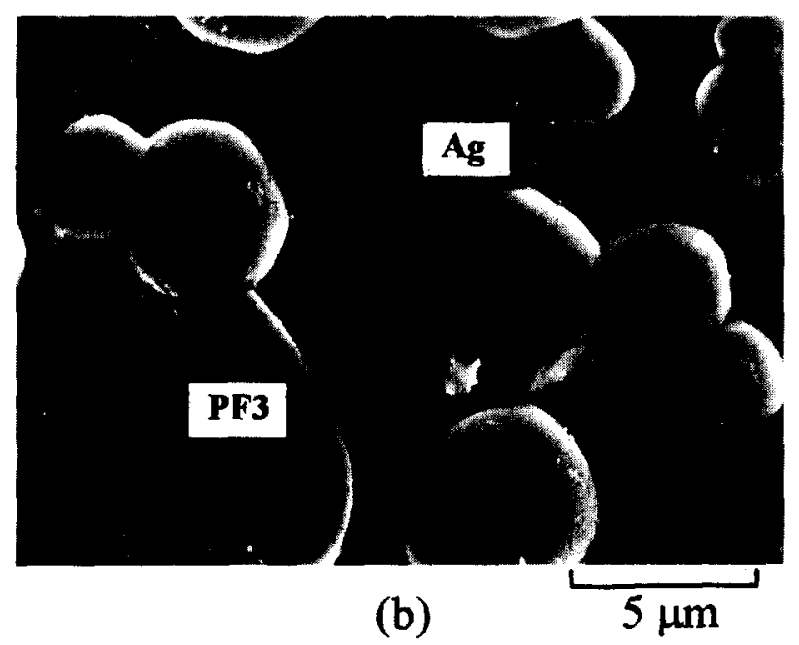

Fig. 2. Scanning electron micrographs of the specimens of silver mixed with (a) PFW and (b) PF3 ceramics after heating at $900^{\circ} \mathrm{C}$ for $2 \mathrm{~h}$.

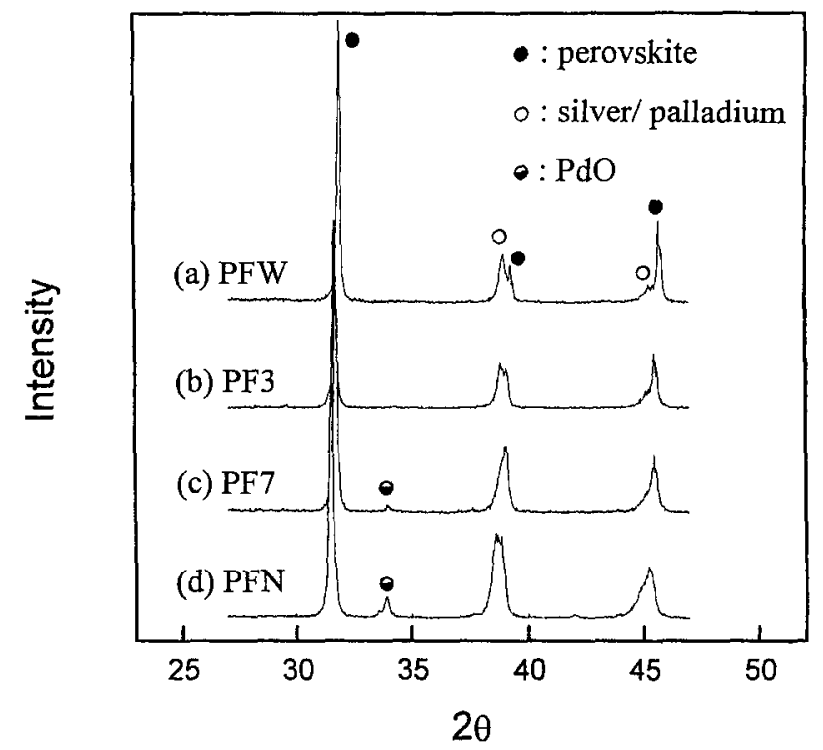

Fig. 3. X-ray diffraction patterns for the specimens of silver/ palladium mixed with (a) PFW, (b) PF3, (c) PF7 and (d) PFN ceramics after heating at $900^{\circ} \mathrm{C}$ for $2 \mathrm{~h}$.

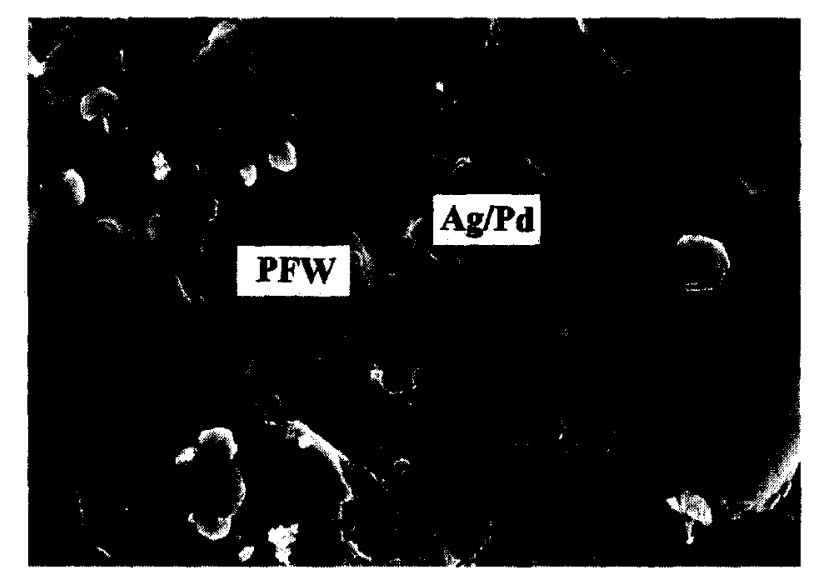

(a)

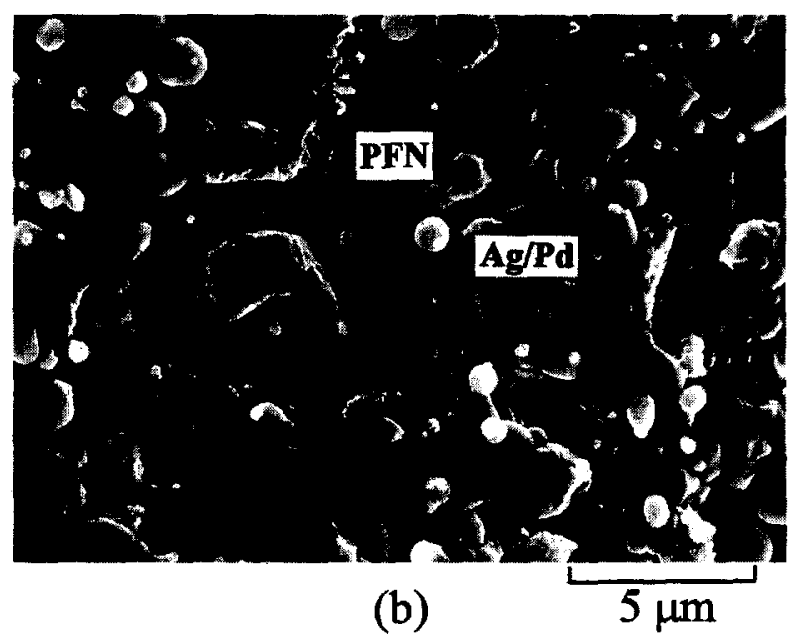

Fig. 4. Scanning electron micrographs of the specimens of silver/palladium mixed with (a) PFW and (b) PFN ceramics after heating at $900^{\circ} \mathrm{C}$ for $2 \mathrm{~h}$. 


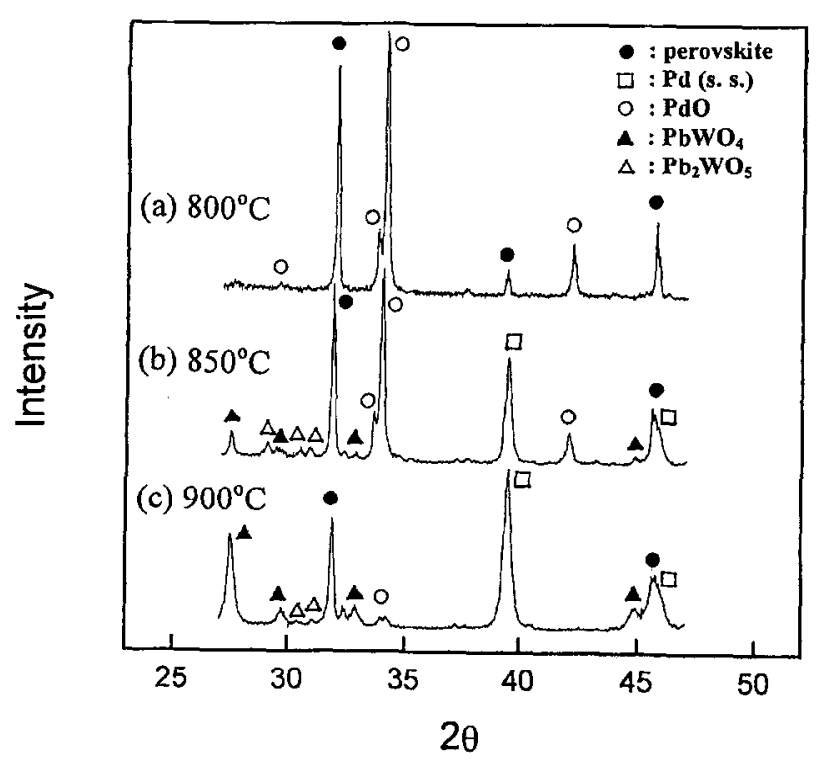

Fig. 5. X-ray diffraction patterns for the mixtures of $\mathrm{PFW}$ and palladium heated at (a) $800^{\circ} \mathrm{C}$, (b) $850^{\circ} \mathrm{C}$ and (c) $900^{\circ} \mathrm{C}$.

of a porous microstructure, indicating that a partial reaction occurred between PFN and the metal.

\subsection{Interaction between PFN/PFW ceramics and palladium}

The reactivity of palladium with the PFN/PFW ceramics was found to be considerably higher than those of silver and silver/palladium with the ceramics. The XRD patterns for the mixture of PFW and palladium vs heating temperatures are shown in Fig. 5. At $800^{\circ} \mathrm{C}$ all palladium was oxidized to become PdO without any variation of PFW. After $850^{\circ} \mathrm{C}$-heating, PFW became unstable and was decomposed to generate lead tungstates $\mathrm{PbWO}_{4}$ and $\mathrm{Pb}_{2} \mathrm{WO}_{5}$. In addition, the diffraction peaks of palladium shifted to the low angle side, implying the formation of a solid solution. At $900^{\circ} \mathrm{C}$, the intensity of $\mathrm{Pb}\left(\mathrm{Fe}_{2 / 3} \mathrm{~W}_{1 / 3}\right) \mathrm{O}_{3}$ was further lowered with an increase in amount of $\mathrm{PbWO}_{4}$, and most of the PdO was reduced.

The reactions of PF3, PF7 and PFN with palladium were similar to each other, but different from that of PFW with palladium. Figure 6 shows the XRD patterns for the heated mixture of PFN and palladium. After $800^{\circ} \mathrm{C}$-heating, PFN kept the same crystal structure associated with the formation of PdO. As the temperature was raised to $850^{\circ} \mathrm{C}, \mathrm{PFN}$ became severely decomposed, and a large amount of a compound exhibiting a pyrochlore structure was formed with a trace of $\mathrm{Fe}_{2} \mathrm{O}_{3}$. Part of the $\mathrm{PdO}$ was reduced to form a palladium-based solid solution. After heating up to $900^{\circ} \mathrm{C}$, most of the PFN was decomposed. It is noted that in PFN-containing specimens, the

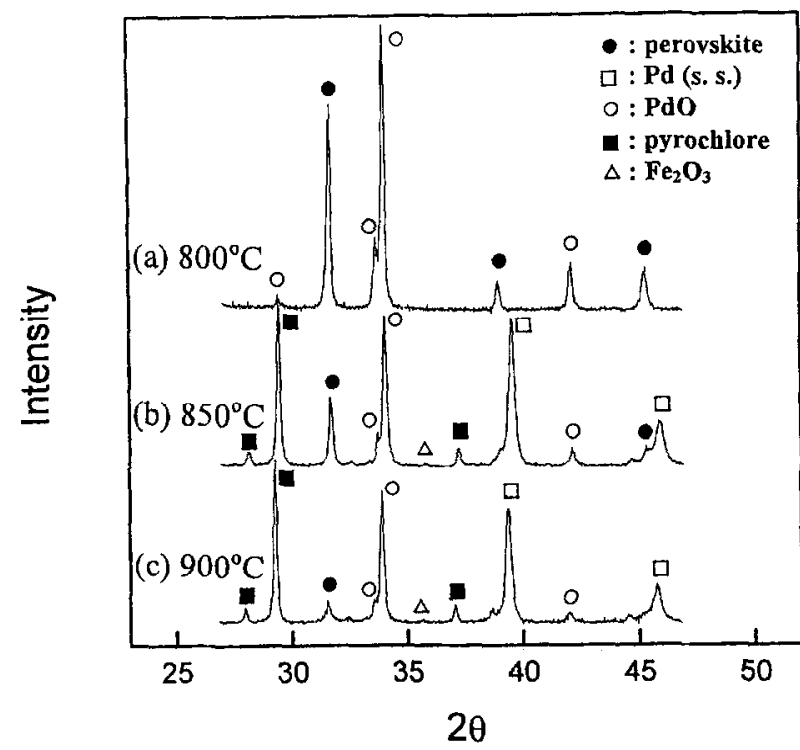

Fig. 6. X-ray diffraction patterns for the mixtures of PFN and palladium heated at (a) $800^{\circ} \mathrm{C}$, (b) $850^{\circ} \mathrm{C}$ and (c) $900^{\circ} \mathrm{C}$.

perovskite phases were decomposed to form pyrochlore phases instead of forming $\mathrm{PbWO}_{4}$ and $\mathrm{Pb}_{2} \mathrm{WO}_{5}$, which were the products after the decomposition of PFW. The formation of the pyrochlore phase was also observed to occur during the reaction between palladium and $\mathrm{Pb}\left(\mathrm{Mg}_{1 / 3} \mathrm{Nb}_{2 / 3}\right) \mathrm{O}_{3}{ }^{3}$

The microstructures of the mixtures of perovskite compounds and palladium did not show significant changes until $850^{\circ} \mathrm{C}$, the temperature at which the decomposition reactions occurred. After decomposition, a large amount of plate-like grains were formed in the mixtures of PFW and palladium [see Fig. 7(a)]. The EDS analysis confirmed these grains to be $\mathrm{PbWO}_{4}$. The finding was in agreement with the results of XRD. The microstructures of decomposed PF3, PF7 and PFN were similar. The granular perovskite grains were decomposed to form small pyrochlore grains, and the microstructures became porous [see Fig. 7(b)]. The EDS analysis indicated that the matrix of palladium with all perovskite compounds contained lead species, implying that a palladium-lead alloy was formed during the reactions. The palladium-lead alloy was also found in the reaction of $\mathrm{Pb}\left(\mathrm{Mg}_{1 / 3} \mathrm{Nb}_{2 / 3}\right) \mathrm{O}_{3}$ with palladium. ${ }^{3}$ The extraction of lead species from PFN/PFW ceramics to form the palladiumlead alloy will cause the perovskite structure to become unstable, thereby inducing the occurrence of decomposition.

The variation of the percentage of perovskite phases in the specimens vs heating temperatures is illustrated in Fig. 8. At $800^{\circ} \mathrm{C}$ only perovskite phases were present in the specimens without the occurrence of the pyrochlore phases. The percentage of perovskite phases was considerably decreased with the increase in temperature. At 


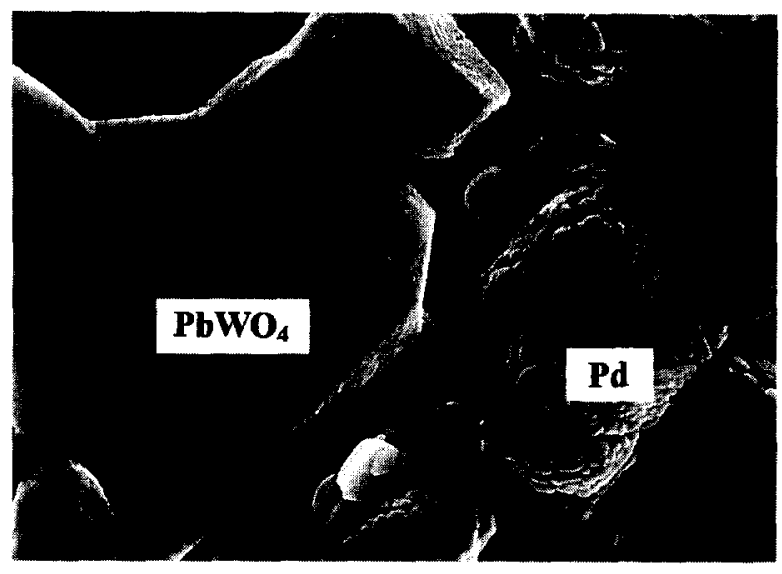

(a)

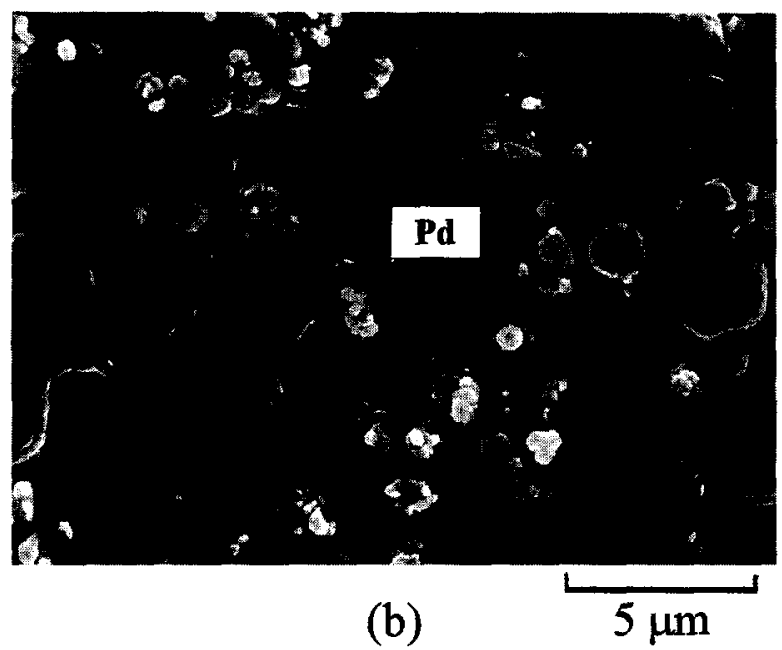

Fig. 7. Scanning electron micrographs of the specimens of palladium mixed with (a) PFW and (b) PF7 ceramics after heating at $900^{\circ} \mathrm{C}$ for $2 \mathrm{~h}$.

$900^{\circ} \mathrm{C}$ the percentage of perovskite phases dropped to become less than $50 \%$ in all specimens. As for PFN, only $10 \%$ of the perovskite phase remained. It is noted that the increase of PFN content tends to greatly decrease the remaining amounts of perovskite phases. This phenomenon indicates that the reactivity of palladium with PFN/PFW ceramics significantly depends on the chemical composition of the ceramics. Increasing the PFN content in ceramics will raise the reactivity of ceramics with palladium, and causes more ceramics to decompose.

For studying the oxidization/reduction reactions of palladium in the various perovskite compounds, thermal analysis experiments were performed. The DTA and TGA results of PF7 reacting with palladium are illustrated in Fig. 9. A broad exothermic peak appeared on the DTA plot at above $250^{\circ} \mathrm{C}$, associated with a weight gain on the TGA plot. This exothermic reaction indicated the oxidization of palladium to form PdO. As the temperatures got higher, an endothermic reaction vigorously arose from $800^{\circ} \mathrm{C}$, with a peak

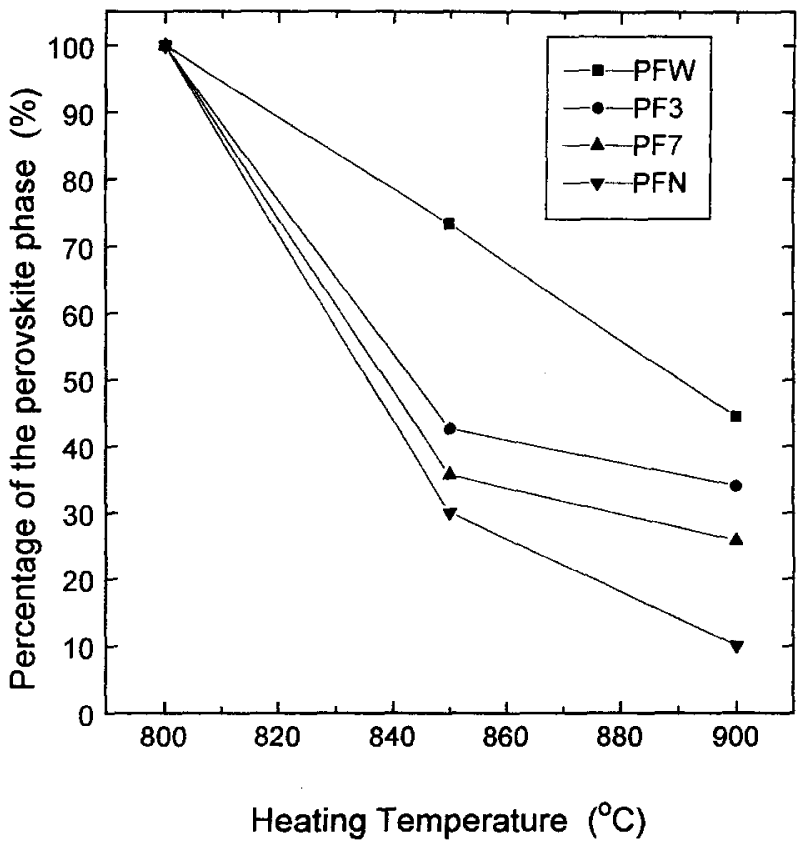

Fig. 8. The relation between the percentage of perovskite phases that remained in ceramics and heating temperatures.

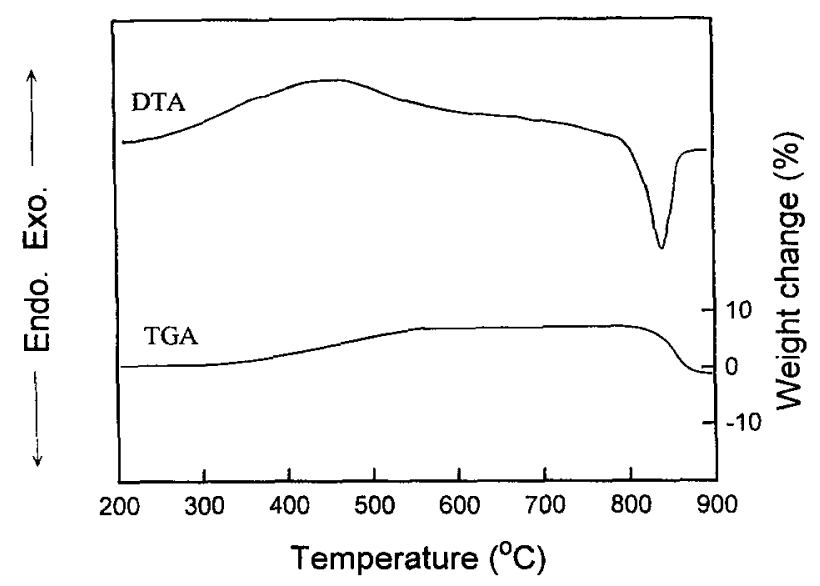

Fig. 9. Differential thermal and thermogravimetric analysis of the mixtures of PF7 and palladium.

temperature at $840^{\circ} \mathrm{C}$. From the onset temperature of this endotherm, the weight of the specimen was found to decrease. This endothermic reaction was caused by the dissociation of PdO to become palladium. Figure 10 illustrates the DTA curves of the perovskite compounds mixed with palladium. All specimens showed a broad exotherm from above $250^{\circ} \mathrm{C}$, indicating the oxidization of palladium. At elevated temperatures, a sharp endotherm caused by the reduction of PdO occurred in all specimens. The temperatures of the endotherm for PFW, PF3, PF7 and PFN were $820^{\circ} \mathrm{C}, 830^{\circ} \mathrm{C}, 840^{\circ} \mathrm{C}$ and $860^{\circ} \mathrm{C}$, respectively. In PFW another small endothermic peak was found at around $860^{\circ} \mathrm{C}$, which was possibly related to the liquid-phase formation caused by the presence of $\mathrm{Pb}_{2} \mathrm{WO}_{5}{ }^{14,15}$ The results in Fig. 10 show that increasing the PFN content 


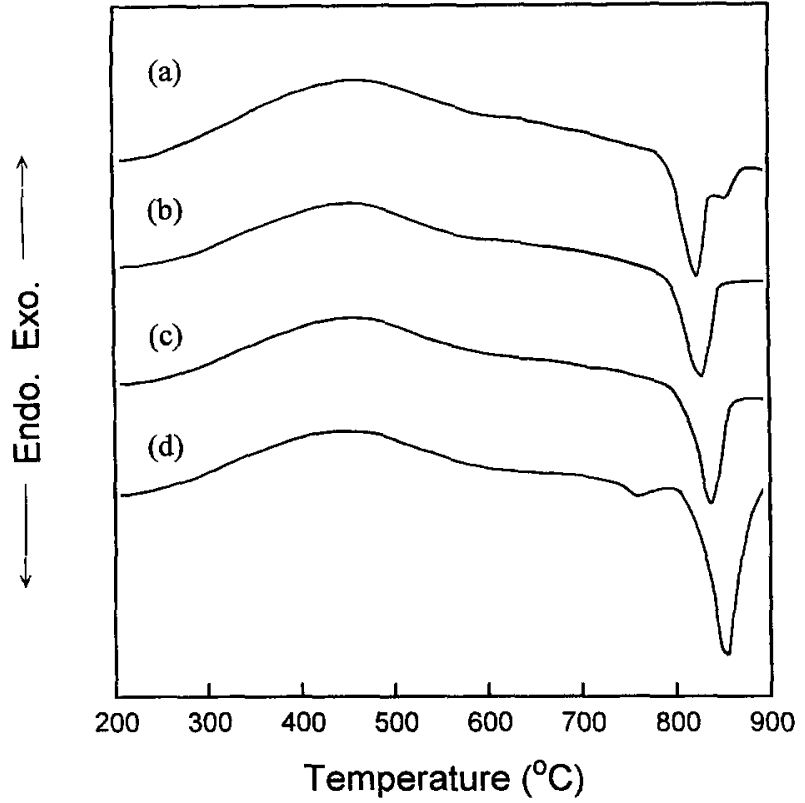

Fig. 10. Differential thermal analysis of the mixtures of perovskite compounds and palladium.

shifted the endotherm to the high-temperature side, implying that the reduction process of PdO was postponed when the content of PFN was increased. The PFN content in PFN/PFW ceramics was found to not only substantially vary the reactivity of palladium with ceramics, but also alter the reduction process of $\mathrm{PdO}$.

\section{CONCLUSIONS}

The interactions of $\mathrm{Pb}\left(\mathrm{Fe}_{1 / 2} \mathrm{Nb}_{1 / 2}\right) \mathrm{O}_{3} \quad(\mathrm{PFN}) /$ $\mathrm{Pb}\left(\mathrm{Fe}_{2 / 3} \mathrm{~W}_{1 / 3}\right) \mathrm{O}_{3}$ (PFW) perovskite ceramics with silver/palladium metals were investigated via the analysis of XRD, SEM and DTA. After heating, pure silver did not react with PFN/PFW ceramics, and ceramic grains maintained their original morphology in the matrix of silver. When the mixtures of the ceramics and $70 \mathrm{Ag} / 30 \mathrm{Pd}$ were heated at $900{ }^{\circ} \mathrm{C}$, the perovskite phases were not significantly changed. However, in the PFN-rich ceramics, the composition of the alloy was varied with a decrease in the palladium content, associated with the formation of PdO. Pure palladium was found to have the highest reactivity with PFN/ $\mathrm{PFW}$. The reactions occurred vigorously from $850^{\circ} \mathrm{C}$ and caused remarkable variation in the microstructures. Palladium induced the decomposition of PFW to form lead tungstates $\mathrm{PbWO}_{4}$ and $\mathrm{Pb}_{2} \mathrm{WO}_{5}$, and resulted in the dissociation of
PFN/PFW ceramics to produce pyrochlore phases and $\mathrm{Fe}_{2} \mathrm{O}_{3}$. The reactivity of PFN/PFW ceramic with palladium was virtually dependent on the chemical composition of the ceramics. Increasing the PFN content led to a rise in the reactivity of palladium with ceramics, which caused more ceramics to decompose. In addition, the increase in the PFN content also postponed the reduction process of PdO to palladium.

\section{REFERENCES}

1. PEPIN, J. G. \& BORLAND, W., Electrode-based causes of delaminations in multilayer ceramic capacitors. $\mathrm{J}$. Am. Ceram. Soc., 72 (1989) 2287-2291.

2. FREIMAN, S. W. \& POHANKA, R. C., Review of mechanically related failure of ceramic capacitors and capacitor materials. J. Am. Ceram. Soc., 72 (1989) 2258-2263.

3. WANG, S. F. \& HUEBER, W., Interaction of silver/ palladium electrodes with lead- and bismuth-based electrodes. J. Am. Ceram. Soc., 76 (1993) 474-480.

4. TAKAMIZAWA, H., UTSUMI, K., YONEZAWA, M \& OHNO, T., Large capacitance multilayer ceramic capacitor. IEEE Trans. Compon., Hybrids. Manuf. Technol., CHMT-4 (1981) 345-349.

5. YONEZAWA, M., Low-firing multilayer capacito materials. Am. Ceram. Soc. Bull., 62 (1983) 1375-1383.

6. JANG, S. J., SCHULZE, W. A. \& BIGGERS, J. V., Lowfiring capacitor dielectrics in the system $\mathrm{Pb}\left(\mathrm{Fe}_{2 / 3} \mathrm{~W}_{1 / 3}\right) \mathrm{O}_{3^{-}}$ $\mathrm{Pb}\left(\mathrm{Fe}_{1 / 2} \mathrm{Nb}_{1 / 2}\right) \mathrm{O}_{3}-\mathrm{Pb}_{5} \mathrm{Ge}_{3} \mathrm{O}_{11}$. Am. Ceram. Soc. Bull., 62 (1983) 216-218.

7. REILEY, T. C., BADDING, J. V., PAYNE, D. A. \& CHANCE, D. A., A low-temperature firing thick film capacitor material based on lead iron niobate/tungstate. Mater. Res. Bull., 19 (1984) 1543-1549.

8. UTSUMI, K. \& YONEZAWA, M., Large capacitance multilayer ceramic capacitor with low firing ceramic material. New Mater. New Process., 3 (1985) 142-149.

9. TAKAHARA, H. \& KIUCHI, K., Dielectric properties of mixed-sintering ceramics in the system $\mathrm{Pb}\left(\mathrm{Fe}_{2 / 3} \mathrm{~W}_{1 / 3}\right) \mathrm{O}_{3}$ $\mathrm{Pb}\left(\mathrm{Fe}_{1 / 2} \mathrm{Nb}_{1 / 2}\right) \mathrm{O}_{3}$. Adv. Ceram. Mater., 1 (1986) 346-349.

10. FU, S. L. \& CHEN, G. F., Low firing thick film dielectrics in the system $\mathrm{Pb}\left(\mathrm{Fe}_{2 / 3} \mathrm{~W}_{1 / 3}\right)_{x}\left(\mathrm{Fe}_{1 / 2} \mathrm{Nb}_{1 / 2}\right) \mathrm{O}_{0.86-x} \mathrm{Ti}_{0.14} \mathrm{O}_{3}$ $\mathrm{Bi}_{2} \mathrm{O}_{3} / \mathrm{Li}_{2} \mathrm{O}$. Am. Ceram. Soc. Bull., 66 (1987) 1397-1400.

11. UTSUMI, K., SHIMADA, Y. \& TAKAMIZAWA, H., Monolithic multicomponents ceramic (MMC) substrate. Mater. Res. Soc. Symp. Proc., 72 (1986) 15-26.

12. SHIMADA, Y., UTSUMI, K., YONEZAWA, M. \& TAKAMIZAWA, H., Properties of the large-capacitance multilayer ceramic capacitor. Jpn J. Appl. Phys., 20 (1981) 143-146.

13. WANG, S. F. \& HUEBER, W., Thermodynamic modelling of equilibrium subsolidius phase relations in the $\mathrm{Ag}$ Pd-O 2 system. J. Am. Ceram. Soc., 74 (1991) 1349-1353.

14. MIZUTANI, N., LU, C. H., SHINOZAKI, K. \& KATO, M., Formation of a high-temperature liquid phase during the sintering of $\mathrm{Pb}\left(\mathrm{Fe}_{2 / 3} \mathrm{~W}_{1 / 3}\right) \mathrm{O}_{3} . J . A m$. Ceram. Soc., 73 (1990) 1214-1220.

15. LU, C. H., Compositional effect on the liquid-phase formation in lead iron tungstate ferroelectric ceramics. J. Am. Ceram. Soc., 77 (1994) 2529-2535. 